\title{
EL DERECHO AL PLAZO RAZONABLE EN LA IMPRESCRIPTIBILIDAD DE DELITOS DE CORRUPCIÓN ${ }^{1}$
}

\author{
The Right to a Reasonable Term in the Imprescriptibility of Crimes of Corruption \\ Uriel Llasacce Orosco ${ }^{2}$ \\ "El derecho viene a perecer menos \\ veces por la violencia que \\ por la corrupción". \\ Enrique Lacordaire.
}

\begin{abstract}
RESUMEN
El legislativo, en aras de luchar contra los actos de corrupción realizados por funcionarios, servidores y el particular o corruptor, que afectan gravemente al Estado, ha optado por la reforma del artículo 41 de la Constitución Política del Estado -Ley $\mathrm{N}^{\circ}$ 30650-que en un extremo prescribe que la acción penal es imprescriptible en los supuestos más graves; ello en la creencia, que tal medida, sería útil para combatir la corrupción y a la vez lograr que, las mismas no queden impunes. Sin embargo, esto no es así, puesto que la imprescriptibilidad de delitos de corrupción lejos de solucionar la corrupción y su impunidad, terminará afectando el derecho fundamental del plazo razonable de las partes agraviado e imputado-, dado que, las investigaciones y procesos penales no tendrán cuando finalizar, por lo que, tal medida es innecesaria, debido a que carece de contribución técnico-jurídico para resolver la corrupción.
\end{abstract}

PALABRAS CLAVES: Plazo Razonable - Imprescriptibilidad Delitos de Corrupción - Derecho Fundamental.

\begin{abstract}
The legislature, in order to fight against acts of corruption carried out by officials, servants and the individual or corruptor, which seriously affect the State, has opted for the amendment of Article 41 of the Constitution - Law No. 30650-, which in a extreme prescribes that the criminal action is imprescriptible in the most serious cases; In the belief that such a measure would be useful to combat corruption and, at the same time, ensure that they do not go unpunished. However, this is not the case, since the statute of limitations of corruption crimes, far from solving corruption and its impunity, will end up affecting the fundamental right of the aggrieved and imputed reasonable period of time, given that criminal investigations and prosecutions will not be finalized. So that such a measure is unnecessary, because it lacks a technical-legal contribution to solve corruption.
\end{abstract}

KEY WORDS: Reasonable Term Imprescriptibility - Crimes of Corruption Fundamental Right.

1 Tema de ponencia en el Coloquio de Graduados "MANUEL G. ABASTOS", llevado a cabo en el II CONGRESO INTERNACIONAL DE DERECHO PENAL Y XV CONGRESO NACIONAL DE DERECHO PENAL Y CRIMINOLOGÍA - CONADEPC LIMA 2018.

2 Abogado por la Universidad Nacional de San Antonio Abad del Cusco (UNSAAC). Asistente en Función Fiscal en la Segunda Fiscalía Provincial Penal Corporativa de Huamanga - Distrito Fiscal Ayacucho. Con estudios de postgrado en Ciencias Penales en la Universidad Nacional de San Cristóbal de Huamanga (UNSCH). Prácticas profesionales en la SUNASS - ODS Cusco, 2014 - 2015. SECIGRA - 2013 en el Ministerio Público Distrito Fiscal Cusco. Y Presidente del Centro Federado de Estudiantes de Derecho de la UNSAAC, 2012.

Correo electrónico: uriel.llasacce.orosco@gmail.com 


\section{ASPECTOS PRELIMINARES}

Todo ciudadano, puede ser pasible de investigaciones $\mathrm{y} / \mathrm{o}$ procesos penales por presuntos actos de corrupción $\mathrm{u}$ otros delitos especiales o comunes. Empero, ello no quiere decir que, en un plazo con dilaciones indebidas o con duraciones interminables tengan que ser investigados, procesados y sancionados, pues tienen derecho a que, en un tiempo prudente conozcan el pronunciamiento de fondo de los casos en que se hallen involucrados, ya sea con decisiones a favor o en contra, de no ser así se estaría violando el derecho al plazo razonable, derecho fundamental que todo justiciable goza, sin importar cual parte fuera -agraviado o imputado-; para evitar ello, es necesario que los afectados con la excesiva duración de la investigación o proceso penal, hagan valer su derecho ante el órgano competente, para fines de obtener una reparación y/o reposición del daño causando.

El flagelo de los actos de corrupción, cada vez es más creciente en diferentes Estados del mundo, de ello no es ajeno Perú. A la fecha, se dramatizó al máximo en el país, tanto así, que en el transcurso de los dos o tres últimos años, se destaparon casos emblemáticos, que por cierto no son nada loables para peruanos que repudian la corrupción, debido a que nos coloca en la tribuna internacional como país de mala reputación; sin embargo, a la vez nos catalogan como un Estado arquetipo que habría emprendido adecuadamente, sancionar actos de corrupción $u$ otros relacionados con este-criminalidad organizada y lavado de activos- desplegando esfuerzos a toda costa, caiga quien caiga, si no recordemos los últimos acontecimientos protagonizados por personalidades públicas del ámbito de la política, así tenemos a exmandatarios del país, tales como el prófugo Alejandro Toledo Manrique, contra quien pesa dos órdenes de prisión preventiva de 18 meses, una por el Caso Ecoteva y otra por Odebrecht; y, Ollanta Humala Tasso y su cónyuge Nadine Heredia Alarcón, por recibir aportes irregulares de parte de la empresa Odebrecht para fines de campañas políticas. Aunado a ello, con acusaciones similares, se tiene el Caso Cócteles que involucra a la lideresa de Fuerza Popular, Keiko Fujimori Higuchi, contra quien se dictó prisión preventiva por 36 meses el pasado 31 de octubre de 2018. De otro lado, los audios de IDLReporteros, terminaron con desmascarar a miembros del Consejo Nacional de la Magistratura, jueces supremos y superiores, vinculados a actos de corrupción, así citamos a algunos de ellos, Iván Noguera Ramos, Cesar Hinostroza Pariachi y Walter Rios Montalvo.

De lo expuesto precedentemente, es comprensible que el Estado ponga en marcha políticas anticorrupción para batallar los delitos de corrupción y evitar que las mismas queden impunes, con ese fin, entiendo que el 20 de agosto de 2017, se publicó en el Diario Oficial El Peruano la Ley $\mathrm{N}^{\circ} 30650$, que reformó el artículo 41 de la Constitución Política del Estado (en adelante (PE), en el extremo de duplicar los plazos de prescripción de delitos de la acción penal, cuando se cometan delitos contra la administración pública o el patrimonio del Estado, así como la imprescriptibilidad en supuestos más graves de corrupción.

Sin embargo, sostengo que esta estrategia no sería útil para solucionar la corrupción en nuestro país, puesto que se seguirán perpetrando cada vez con mayor genialidad, aprovechando que los agentes de estos delitos emplean conocimientos relacionados con el sistema judicial, son asesorados jurídicamente y blindados por operadores de la justicia, conformando de este modo una red criminal enlazando las principales esferas de la estructura de Estado.

Por ello, apuesto que la mejor manera de luchar y poner fin a la corrupción, es aplicando políticas de prevención a través de la educación, pienso que aquí estaría el antídoto anticorrupción. Por ende, es una medida innecesaria la imprescriptibilidad de delitos de corrupción, por más que solo opere en los delitos más graves. 


\section{EL PLAZO RAZONABLE Y SU REGULACIÓN NORMATIVA}

\subsection{El derecho al plazo razonable a modo de definición}

En principio corresponde definir en qué consiste el plazo, al respecto la Real Academia Española, enseña que la palabra "plazo" proviene de la locución latina placitum que se significa "convenido", término o tiempo señalado para algo; mientras tanto, la palabra "razonable" emana del latín rationabilis que quiere decir, adecuado, conforme a razón. En consecuencia por plazo razonable se debe entender, el tiempo fijado o adecuado en el cual se debe materializar una acción concreta.

En la doctrina se ha consensuado que, "plazo es el espacio de tiempo dentro del cual debe ser realizado un acto procesal y que este concepto debe diferenciarse del término, que indica el momento concreto en que se realiza una acción, con expresión del día y hora en que debe verificarse" (Neyra, 2010, p. 149). En consecuencia, el plazo razonable debe concebirse como todo aquel proceso que se desarrolla desde su inicio hasta el final en un tiempo prudente - no dilatorio-, sin importar su naturaleza penal o extrapenal; es decir, un lapso de tiempo de no muy corto ni largo plazo, donde se debe realizar un conjunto de procedimientos o actos procesales (Melgarejo, 2011). Al respecto el Tribunal Constitucional peruano (en adelante TC), se pronunció ilustrando, "Razonable es un término que expresa una exigencia de equilibrio en cual estén moderados armoniosamente, por un lado la instancia de una justicia administrada sin retardos $\mathrm{y}$, por otro, la instancia de una justicia no apresurada y sumaria" (Tribunal Constitucional, STC Exp. N. ${ }^{\circ}$ 010-2002-AI/TC F.J. 166).

Así también, el plazo razonable viene a ser uno de los derechos integrantes que se desprende del debido proceso. En relación a ello, el TC ha sostenido, "Es posible identificar dentro del contenido de un derecho expresamente reconocido otro derecho que, aunque susceptible de entenderse como parte de aquel, es susceptible de ser configurado autónomamente. Adiciona [...] el derecho al plazo razonable es un contenido implícito del derecho al debido proceso y que tales contenidos implícitos de los derechos viejos no deben ser confundidos con los derechos nuevos o no enumerados" (Pestana, 2009). En ese mismo sentido, la jurisprudencia casatoria vinculante $\mathrm{N}^{\circ} 66-2010$, aclaró que, "el plazo razonable es un derecho integrante del debido proceso que constituye un derecho fundamental de toda persona a ser juzgada penalmente en forma adecuada, rápida y eficaz" (Corte Suprema de Justicia, Casación $\mathrm{N}^{\circ}$ 662010). El cual da a entender que, sólo de esta manera en un proceso penal o en una investigación preliminar o prejurisdiccional, se garantizará a las partes un proceso e indagación libre de arbitrariedades y excesivas duraciones indebidas de actos procesales y/o investigación.

\subsection{El plazo razonable y su regulación en la normativa supranacional y nacional}

Distintos instrumentos internacionales se han encargado de regular y definir el plazo razonable, cada una de ellas de distintas formas, tratando en el fondo precisar el mismo significado. Así tenemos que, la Convención Americana sobre Derechos Humanos (en adelante $\mathrm{CADH}$ ) en su artículo 7.5 prescribe: "Toda persona detenida o retenida debe ser llevada, sin demora, ante un juez $u$ otro funcionario autorizado por la ley para ejercer funciones judiciales y tendrá derecho a ser juzgado dentro de un plazo razonable o a ser puesta en libertad, sin perjuicio de que continúe el proceso [...]"; asimismo el artículo 8.1 de la Convención acotada, señala: "Toda persona tiene derecho a ser oída, con las debidas garantías y dentro de un plazo razonable, [...]". De otro lado, el Pacto Internacional de Derechos Civiles y Políticos (en adelante PIDCP) en su artículo 9.3 codifica: "Toda persona detenida o presa a causa de una infracción penal [...] tendrá derecho a ser juzgada dentro de un plazo razonable o a ser puesta en libertad [...]". 
El plazo razonable, también se encuentra expreso en el Convenio Europeo para la Protección de los Derechos Humanos y de las Libertades Fundamentales de 1950 (en adelante CEDH). Al respecto, la propia Corte Interamericana de Derechos Humanos (en adelante Corte IDH), ha señalado que, "El artículo 8.1 de la Convención Americana de Derechos Humanos, [...] es equivalente en lo esencial, al artículo 6 del Convenio Europeo para la Protección de los Derechos Humanos y de las Libertades Fundamentales [...]" (Corte Interamericana de Derechos Huamanos, Caso Genie Lacayo vs. Nicaragua F.J. 77, 1997). En esa línea, el artículo 6.1 del CEDH prescribe que, "Toda persona tiene derecho a que su causa sea oída públicamente y dentro de un plazo razonable, por un tribunal independiente e imparcial sobre el fundamento de cualquier acusación en materia penal [...]".

Por otro lado, cabe aclarar que la $\mathrm{CPE}$, no regula forma expresa el derecho al plazo razonable; sin embargo, si recurrimos a la interpretación sistemática, hallamos que este derecho es parte integrante del debido proceso y de la tutela jurisdiccional -artículo 139 numeral 3 de la Constitución. "Son principios y derechos de la función Jurisdiccional: La observancia del debido proceso y la tutela jurisdiccional"-; es decir, que a pesar de no estar de forma explícita en la Constitución, ello no significa que no exista en el ordenamiento interno de nuestro país, pues a través de los instrumentos internacionales que el Perú ratificó y suscribió, forman parte del cuerpo normativo nacional. En cambio, en el Código Procesal Penal de 2004 (CPP), el plazo razonable si se encuentra reglamentado en el numeral 1 del artículo I del Título Preliminar, siendo su redacción: "1. La justicia penal [...] Se imparte con imparcialidad por los órganos jurisdiccionales competentes y en un plazo razonable".

\section{LA PRESCRIPCIÓN DE LA ACCIÓN PENAL}

\subsection{Prescripción e imprescriptibilidad}

Para el maestro español Muñoz Conde, la prescripción viene a ser una causa de la extinción de la responsabilidad criminal fundada en la acción del tiempo sobre los acontecimientos humanos, su fundamentación radica más en razones de seguridad jurídica. Se trata de impedir el ejercicio del poder punitivo, una vez que ha trascurrido determinados plazos a partir de la comisión del delito o del pronunciamiento de la condena, sin haberse cumplido la sanción (Muñoz, 1999). En ese mismo sentido, el peruano Prado Saldarriaga, define a la prescripción, como el transcurso del tiempo que extingue la persecución de un delito o la ejecución de una pena. No obstante, en un plano más técnico se identifica a la prescripción como la perdida, por parte del Estado, de la facultad de ejercitar en un caso concreto el ius puniendi (Prado, 1996).

Cabe aclarar, que en este extremo, solo me avocaré a la prescripción de la acción penal, dejando de lado a la prescripción de la pena, puesto que no guarda relación con la duración del plazo razonable en la investigación preliminar y/o proceso penal. Aclarado ello, por prescripción de la acción penal, se entiende como aquel que delimita en el tiempo la obligación que tiene el Estado para investigar, perseguir, juzgar y sancionar un hecho penalmente relevante. Si transcurrido el plazo, previamente determinado por el legislador, el Estado no ha hecho efectivo el ius puniendi, se elimina toda incertidumbre jurídica y se abandona la sanción penal, consagrando de esta manera el principio de seguridad jurídica (Loza, 2017).

A contrario sensu, la imprescriptibilidad de un delito, es la condición de un hecho delictivo que no puede ampararse en su invalidez por el paso del tiempo. Imprescriptible significa que no puede prescribir, es decir, que no pierde vigencia ni perece por el transcurso del tiempo. Un derecho imprescriptible es un derecho que nunca perderá validez (https://quesignificado.com/imprescriptible/). En consecuencia, jurídicamente por 
imprescriptibilidad se entenderá, como la inexistencia de un plazo que permita la extinción de la acción penal o de la ejecución de la pena, por el transcurso del tiempo; es decir, los delitos no prescriben, estarán activos ad infinitum su persecución y ejecución, como bien ocurre con los delitos de lesa humanidad, tales como: asesinato, exterminio, tortura, desaparición de personas y actos inhumanos.

\subsection{La prescripción de la acción penal en el Código Penal peruano}

Nuestro Código Penal, regula las reglas de aplicación de la prescripción para los tipos penales previstos en el mismo. Así en el artículo 80 , fija los plazos de prescripción de la acción penal, precisando en el primer párrafo que la acción penal prescribe en un tiempo igual al máximo de la pena fijada por la ley para el delito (prescripción ordinaria); no siendo esta la única, puesto que, el artículo 83 también ordena otra regla de prescripción, basándose en la interrupción de la prescripción de la acción penal establece que, la acción penal en estos casos prescriben cuando el tiempo transcurrido sobrepasa en una mitad al plazo ordinario de prescripción (prescripción extraordinaria).

Aunado a ello, la Corte Suprema de la República, estableció como doctrina legal, que el Código Penal distingue de manera sistemática $\mathrm{y}$ funcional dos clases de plazos para la prescripción de la acción penal; el artículo 80 regula la prescripción del plazo ordinario, mientras tanto el artículo 83 in fine el plazo de la prescripción extraordinaria. Precisando que, cuando se trate de delitos cuya pena conminada privativa de libertad tiene un máximo legal superior a 20 años, el plazo ordinario de prescripción de la acción penal será 20 años, y el plazo extraordinario de prescripción de la acción penal, 30 años; y, cuando la pena que reprime el delito sea de cadena perpetua, el plazo ordinario de la prescripción de la acción penal será de 30 años, y el plazo extraordinario de prescripción de la acción penal, 45 años (Acuerdo Plenario $\mathrm{N}^{\circ}$ 09-2007/CJ-116, FJ. 06 y 10).
Volviendo a citar el artículo 80 del Código Penal, cabe precisar que en la parte in fine transcribe un plazo de prescripción especial, esto es, la duplicidad del plazo de prescripción en delitos de corrupción cuando se afecte el patrimonio del Estado -vigente aún pese a la reforma del artículo 41 de la Constitución, Ley N 30650-, siendo su redacción lo siguiente: "En casos de delitos cometidos por funcionarios y servidores públicos contra el patrimonio del Estado [...] el plazo de prescripción se duplica". Si la interrogante sopesa en determinar, cuáles serían los delitos en los cuales se afecta el patrimonio del Estado, no habría mejor respuesta que el delito de peculado y malversación de fondos, conforme concluye Pariona Ariana (2012) al analizar el Acuerdo Plenario $N^{\circ}$ 01-2010.

Además, es meritorio dar a conocer, de qué manera la Corte Suprema de la Republica, ha ido concordando la jurisprudencia penal -doctrina legal-dictando acuerdos plenarios respecto de la prescripción, así tenemos el Acuerdo Plenario $\mathrm{N}^{\circ}$ 01-2010/CJ-116 de fecha 16 de noviembre de 2010 y el Acuerdo Plenario No 03-2012/CJ-116 de fecha 26 de marzo de 2012. El primero, se debatió bajo la problemática de "Prescripción: Problemas actuales", en el cual se trató: i) La determinación de los alcances del último párrafo del artículo 80 del Código Penal: duplica de la prescripción cuando el delito es cometido por un funcionario o servidor público contra el patrimonio del Estado; ii) La prescripción extraordinaria y la configuración y efectos de la reincidencia en las faltas; y, iii) Establecer el sentido del artículo 339 del Código Procesal Penal que dispone la suspensión de la prescripción cuando se formaliza la investigación preparatoria (Acuerdo Plenario $\mathrm{N}^{\circ} 01-2010 / \mathrm{CJ}-$ 116, F.J. 9, 10 y 11).

De lo expuesto, relacionado con el trabajo que me convoca, es lo referido en el punto i), puesto que, en el VI pleno jurisdiccional de 2010, se ha aclarado que el incrementó -duplicidad- del plazo de la prescripción es sui generis, debido a 
que solo operará en delitos cometidos por funcionarios y servidores públicos que afecten el patrimonio del Estado, el cual es importante para que el actuar delictual de dichas personas no queden impunes; asimismo, ayuda en gran medida al persecutor del delito, puesto que tendrá un mayor tiempo para materializar actos de investigación que permitan esclarecer el caso que venga investigando.

Mientras tanto, el Acuerdo Plenario $\mathrm{N}^{\circ}$ 032012/CJ-116, es consecuente al Acuerdo Plenario $\mathrm{N}^{\circ}$ 01-2010/CJ-116 en el extremo del punto iii), suspensión de la prescripción cuando se formaliza la investigación preparatoria; acerca de ello, en el I pleno jurisdiccional extraordinario de 2012, ante la insistencia de la doctrina minoritaria y de la judicatura nacional, respecto a la problemática de lo previsto en el artículo 339 del Código Procesal Penal, en el sentido de que, la suspensión debe ser entendida como interrupción, toda vez que esta última habría sido modificada o derogada por la primera; al respecto, en dicho pleno se ha aclarado que la suspensión e interrupción son disposiciones independientes aunque aludan a una misma institución penal -suspensión de la prescripción de la acción penal-, se trata solo de disposiciones compatibles que regulan cada una causales distintas de suspensión de la prescripción de la acción penal que puedan operar de modo secuencial, paralelo o alternativo; por otra parte, en este mismo acuerdo plenario, también se precisó el límite temporal de duración de la suspensión de la prescripción de la acción penal, siendo ello que, no podrá prolongarse más allá de un tiempo acumulado equivalente al plazo ordinario de la prescripción más una mitad de dicho plazo (Acuerdo Plenario $\mathrm{N}^{\circ}$ 03-2012/CJ116, F.J. 10 y 11).

\section{PROBLEMÁTICA ACTUAL DE LA CORRUPCIÓN EN PERÚ}

Vertiginosamente precisaré que la corrupción en nuestro país, no es un tema de los últimos años, sino data desde tiempos remotos, época de la colonia siglo XVI, la historia registra que desde aquellos tiempos se produjo ganancias irregulares e indebidas, que alimentaban interés particulares del aparato de la corona española. Posteriormente, hasta finales del siglo XX, temas de corrupción no eran frecuentes escuchar a través de los diferentes medios de comunicación, empero tras la caída del régimen dictatorial de Alberto Fujimori Fujimori, salieron a la luz actos de corrupción liderados por personas integrantes de las altas esferas del poder del Estado; por lo que, a partir del gobierno de Alejandro Toledo Manrique (2000), políticamente intentaron y reintentaron a través de distintos proyectos de ley -algunos incluso con nombre propio-, batallar contra actos de corrupción, situación que fue aprovechada por la clase política, para captar votos de electores, alegando que la imprescriptibilidad para delitos de corrupción supuestamente sería la arma idónea para frenar la corrupción. Sin embargo, desde la óptica del derecho, dicha institución jurídica no sería la adecuada para combatir y/o erradicar la corrupción, tampoco idóneo para resolver su impunidad.

A la fecha, la corrupción en Perú se propagó como si fuese una epidemia, pues conforme la encuesta publicada en El Comercio, realizada a nivel nacional urbano-rural con apoyo de Ipsos, muestra que la corrupción es el principal problema del país en la actualidad, un $57 \%$ de entrevistados lo considera así. Este primer lugar no se repetía desde el 2010. La delincuencia y la falta de seguridad se ubican en segundo lugar con $55 \%$. Le siguen una educación inadecuada con $31 \%$ y el desempleo y la falta de trabajo con $25 \%$ (El Comercio, 2018). Ahora bien, cabe preguntarnos qué es la corrupción, según Transparencia Internacional sería, "el uso indebido de poder otorgado para beneficio privado. La corrupción entraña conductas por parte de funcionarios en el sector público o sus allegados, por las cuales se enriquecen indebida e ilegítimamente mediante el mal uso del poder que se les ha confiado" (Proyecto de Ley, Reforma del Art. 41 de la Cosntitución Política del Estado, 2016). 
El problema es tan grave, que la Federación Internacional de Derechos Humanos (FIDH), ONG internacional de defensa de los derechos humanos que agrupa a 184 organizaciones nacionales de derechos humanos de 112 países, ha publicado en abril de 2018, citando el Reporte de la Corrupción en el Perú a mayo de 2017, elaborada por la Defensoría del Pueblo, que en nuestro país, "se estima que la corrupción le cuesta al país 12,000 millones de soles cada año, es decir más de 3,600 millones de dólares. Esto equivale a que diariamente, la corrupción le arranca unos 10 millones de dólares a Perú. Una situación que, en últimas, termina por afectar el bolsillo de los ciudadanos pues el precio de la corrupción asciende al $10 \%$ del presupuesto nacional por año" (FIDH - La corrupción socava la democracia y el acceso a los derechos fundamentales, 2018, p. 7).

El Estado hace mal en optar políticas de represión, traducidas en endurecimientos de penas u otras similares, como bien podría ser declarar imprescriptibles los delitos más graves de corrupción, puesto que estas formas de estrategia o mecanismos de lucha contra la corrupción, no ahuyentan, menguan o solucionan, que funcionarios, servidores y el particular corruptor, no incurran en actos de corrupción. Por lo que, en mi modesta opinión, no habría mejor instrumento para batallar la corrupción y evitar que las mismas queden impunes, que apostar por la educación. Por otro lado, algunos juristas sostienen que, los involucrados en delitos de corrupción alegarían o efectuarían conductas obstruccionistas para conseguir la tan ansiada prescripción, logrando de este modo no ser pasibles de una sanción penal; de ser ello así, no hay que olvidar que el actuar apático del Estado en el ejercicio de sus facultades de investigar, procesar y sancionar a los agentes de delitos de corrupción, es de su entera responsabilidad; peor aún, cuando la gran mayoría de los delitos de corrupción, sobre todo los que afectan el patrimonio del Estado o erario nacional, estén sancionados con varios años de pena privativa de libertad.
En consecuencia, no podemos justificar la desidia de los operadores de justicia en cuanto a sus funciones propias de impartir y administrar justicia, indicando que para su mejor actuar requerirían la imprescriptibilidad; acoger esto, sería practicar políticas de anticorrupción inútiles, que solo servirían para que la clase política del país llame la atención de los electores. Pero como dice, el tan trillado refrán o máxima, "la esperanza es lo último que se pierde", en consecuencia hay esperanzas que el Perú un día tenga cero corrupción, la solución estaría en la educación -política criminal de prevención-, pues a través de ella, niños y jóvenes, mediante el aprendizaje internalizarían en su memoria que la corrupción significa destrucción del Estado, por ende empobrecimiento de sus habitantes.

\section{POSICIONES A FAVOR Y EN CONTRA SOBRE LA IMPRESCRIPTIBILIDAD DE LOS DELITOS DE CORRUPCIÓN}

Al respecto, distintos hombres del derecho, así como también instituciones competentes, han expuesto sus puntos de vista sobre los pros y contra de la imprescriptibilidad de delitos de corrupción, algunos fundamentándolos adecuadamente, otros acudiendo a argumentos forzados, así tenemos los siguientes:

\subsection{Argumentos a favor: La imprescriptibilidad combatiría la impunidad de los delitos de corrupción o por lo menos tendría carácter disuasivo}

Quienes están a favor, sostienen que la imprescriptibilidad sería una forma de combatir la impunidad de los delitos de corrupción, puesto que funcionarios, servidores y el corruptor, podrán merecer la sanción penal que les corresponde si los hallaran culpables de la comisión de delitos de corrupción, y a la vez, no siendo tan jactanciosos aseguran que la imprescriptibilidad por lo menos tendría carácter 
disuasivo, ya que sería un instrumento eficaz para combatir la corrupción. Sin embargo, juristas adversos a esta posición, plantean que la imprescriptibilidad no sería la herramienta adecuada para combatir la impunidad de los delitos de corrupción, mucho menos era necesaria acudir a ella a través de la modificatoria del artículo $49^{\circ}$ de la Carta Fundamental, considerando que otros son los problemas que deberían atacarse si queremos resolver la corrupción en Perú.

Uno de los juristas que, se mostró a favor de la imprescriptibilidad de los delitos de corrupción apenas se publicó la Ley 30650 el 20 de agosto de 2017, en el Diario Oficial El Peruano, que reformó el artículo 41 de la CPE, en el sentido de establecer la imprescriptibilidad de los delitos más graves contra la administración pública o contra el patrimonio del Estado, fue el doctor Cesar Landa Arroyo, quien desarrollando el test o juicio de proporcionalidad, justifica que la imprescriptibilidad de los delitos cometidos por funcionarios públicos resulta proporcional $\mathrm{y}$, en consecuencia compatible con el marco jurídicoconstitucional vigente (Legis.pe, 2017).

Dicho jurista analizando el sub principio de la idoneidad, señala que, "[...] los niveles de corrupción no solo afectan la dimensión institucional del Estado, sino que el Perú pierde al año unos 3 millones de dólares debido a la corrupción. Este dinero pudo haber sido destinado a obras de infraestructura, saneamiento, construcción de hospitales o colegios [...] la imprescriptibilidad de los delitos de corrupción de funcionarios tiene como finalidad el garantizar la plena vigencia de los derechos humanos [...]". Así también, considerando la necesidad, haciendo referencia el artículo 41 de la CPE antes de su modificatoria en agosto 2017, sustenta que, “[...] el artículo 41, en su último párrafo señala que "el plazo de prescripción se duplica en caso de delitos cometidos contra el patrimonio del Estado". Si bien esta medida es menos lesiva en comparación al presente proyecto de ley, no es igualmente idónea [...] la prescripción como limite al poder punitivo del Estado se ha convertido en un arma eficaz para lograr la impunidad [...]". Finalmente, respecto a la proporcionalidad en sentido estricto, postula que, "[...] la prescripción de la acción penal permite la optimización del derecho al plazo razonable del proceso [...] la intervención a este derecho fundamental es media. Ello debido a que la limitación al derecho a tener un juicio sin dilaciones no incluye la eliminación de otras garantías inmersas en el derecho al debido proceso [...]. Por lo tanto, la satisfacción alta que causa la modificación del artículo 41 de la Constitución frente a la intervención media del derecho al debido proceso de los funcionarios públicos cumple con los parámetros de razonabilidad y proporcionalidad" (Morante, 2017).

De ello, se colige que, el fin que se persigue con la imprescriptibilidad, es evitar la impunidad de quienes incurrieron en delitos de corrupción, siendo la imprescriptibilidad el medio para alcanzar tal fin, o por lo menos sería un aporte con cual combatir la corrupción (idoneidad). Pese a la existencia de una medida menos gravosa, como la ampliatoria del plazo de prescripción, considera que esta no sería el adecuado para la lucha contra la corrupción, puesto que sería mucho mejor acudir a una medida más gravosa, la imprescriptibilidad (medida necesaria). Y por último, justifica que, si bien se afectarían derechos fundamentales como el debido proceso que comprende el derecho al plazo razonable, empero esa afectación sería menor, toda vez que la santificación que se conseguirá con la imprescriptibilidad será mayor, ya que impediría la impunidad de delitos de corrupción, puesto que la perpetración de estos delitos también violentarían derechos fundamentales (proporcionalidad in strictu sensus).

\subsection{Argumentos en contra: La imprescriptibilidad no combatiría la impunidad de delitos de corrupción y,}




\section{afectaría principios y derechos fundamentales}

Por otro lado, existen juristas que no armonizan con la imprescriptibilidad de delitos de corrupción, es el caso del maestro Raúl Pariona Arana, a quien no le falta razón al sostener que, declarar imprescriptibles los delitos de corrupción no solucionaría el problema de su impunidad, puesto que contravendría principios fundamentales del derecho penal, siendo ilegítima y contraproducentes para la lucha contra la impunidad; es más no sería necesaria esta medida. Considera que la imprescriptibilidad de delitos de corrupción abriría camino a un derecho penal sin garantías, puesto que la potestad del Estado de perseguir estos delitos no se extinguiría nunca, se mantendrían de por vida como una espada de Damocles para adversarios políticos; el Estado estaría renunciando al deber de resolver causas judiciales con celeridad, pues al no prescribir los delitos no podría controlarse los plazos de duración del proceso, no existiría presión para resolver las causas con prontitud; por ello, propuso duplicar los plazos de prescripción para todo los delitos cometidos por funcionarios públicos con abuso de cargo o función (Pariona, 2012).

Otro jurista que se mostró en contra de la imprescriptibilidad de delitos de corrupción fue Roberto Pereira Chumbe, quien opina que la imprescriptibilidad carece de razonabilidad, puesto que propiciaría investigaciones y procesos interminables, vulnerándose de este modo el derecho de obtener una decisión en un plazo razonable; asimismo incrementaría el riesgo de errores judiciales, ya que el transcurso excesivo del tiempo afectaría la calidad de la prueba sobre los hechos (Pereira, 2016).

Aunado a ello, el 29 de noviembre de 2016, la Defensoría del Pueblo como órgano constitucional autónomo, tras la remisión de los proyectos de ley Nros. 116/2016-CR, 119/2016CR, 121/2016-CR, 122/2016-CR y 127/2016-CR por parte de las Comisiones de Justicia y Derechos Humanos, Constitución y Reglamento del Congreso de la Republica, ha emitido su opinión a través del Informe $\mathrm{N}^{\circ}$ 001-2016P/APCSG-PEPPCPP, haciendo conocer que la imprescriptibilidad de la acción penal para delitos de corrupción no superaría el test de proporcionalidad debido a que no habrían vencido el examen de idoneidad y necesidad, puesto que el tiempo con lo que se cuenta para la investigación -preliminar y preparatoria- es idóneo para procesar y sancionar a funcionarios y servidores corruptos antes que éstos se amparen en la prescripción; así también, enfatizó que no se estaría tomando en cuenta medidas menos gravosas como bien puede ser la ampliación del plazo prescriptorío, por lo que, calificó dichos proyectos de ley como desproporcionados.

\section{EFECTOS DE LA IMPRESCRIPTIBILIDAD DE LOS DELITOS DE CORRUPCIÓN: APRECIACIÓN PERSONAL}

$\mathrm{Si}$ hacemos un parangón entre los beneficios y perjuicios de la imprescriptibilidad de delitos de corrupción, considero que este último será el que en un futuro se presentará con mayor frecuencia en nuestro sistema judicial, pues si bien es cierto, tras la Ley de Reforma del artículo 41 de la Constitución Política del Perú -Ley N 30650-, en el extremo de que, "El plazo de prescripción de la acción penal se duplica en casos de los delitos cometidos contra la Administración Pública o el patrimonio del Estado, tanto para los funcionarios o servidores públicos como para los particulares. La acción penal es imprescriptible en los supuestos más graves, conforme al principio de legalidad" (Diario Oficial El Peruano, 2017). Al respecto, la prensa hablada y escrita del país, han informado en su gran mayoría reacciones de elogio por parte de juristas, políticos y ciudadanos de a pie, en el sentido, de que el congreso habría hecho una adecuada labor al aprobar la aludida Reforma Constitucional, puesto que contarían con una herramienta útil para enfrentar la impunidad de los delitos de corrupción; empero, desde el punto de vista técnico-jurídico, juristas reconocidos, criticaron que tal reforma no estaría aportando 
nada para luchar contra la ola de corrupción que azota cada vez a mayor escala al país, puesto que ello solo obedecería a intereses electoreros de algunos políticos, mismo que lo suscribo, acotando que ni siquiera tendría un contenido disuasivo.

A propósito de la reforma constitucional del artículo 41 de la Carta Magna, en el extremo de que, “(...) La acción penal es imprescriptible en los supuestos más graves, conforme al principio de legalidad"; corresponde definir, cuáles serían los ilícitos penales más graves que se adecuarían a la imprescriptibilidad de la acción penal. En principio claro está, que a la fecha aún no se modificó el artículo 80 del Código Penal -norma que necesariamente deberá regular expresamente la imprescriptibilidad de la acción penal-, tampoco dicha norma registra el catálogo de tipos con el nomen iuris de "delitos de corrupción graves o más graves", que es lo mínimo que deberá contener la norma sustantiva para su correcta aplicación de la modificatoria constitucional en mención. Pese a ello, se debe entender por delitos de corrupción más graves, a aquellos ilícitos penales que a consecuencia de su consumación afectan directamente el patrimonio del Estado, mismos que a la vez cuentan en su mayoría con sanciones draconianas, entre 10 a 15 años de pena privativa de libertad; en consecuencia, siguiendo este razonamiento, me atrevería a sostener que el legislador al momento de determinar en la legislatura correspondiente la interrogante ¿cuáles serían los delitos de corrupción más graves?, detallará principalmente como tales: el delito de colusión agravada, cohecho específico, peculado agravado e enriquecimiento ilícito.

Ahora bien, una de las consecuencias principales de la imprescriptibilidad de los delitos de corrupción a nivel de la etapa de la investigación preparatoria del proceso penal, es que en los años venideros, se quebrantará el derecho al plazo razonable, puesto que, las investigaciones preliminares y/o preparatorias por parte de las Fiscalías Especializadas en Delitos de
Corrupción de Funcionarios tendrán a favor la perpetuidad para efectuar actos de investigación, ya que serán conscientes de que la persecución penal que activaron, no les jugará en contra. Del mismo modo, los jueces de garantías -quienes despachan los juzgados de investigación preparatoria- de oficio $\mathrm{o}$ a petición del investigado o procesado, no podrán efectuar a cabalidad el control de plazos en los procesos penales, o bien realizándolos mostraran apatía, puesto al advertir que los delitos por cual se vienen procesando están encuadrados bajo el supuesto de más graves, serán imprescriptibles.

Lo mismo sucederá en la etapa intermedia y juicio oral del proceso penal, pues si bien, en estas etapas el persecutor de la acción penal, tiene finiquitado su teoría del caso y está convencido que llegado la audiencia preliminar de control de acusación, podrá demostrar que la relación de medios de prueba que viene ofreciendo para la etapa estelar del juicio oral son conducentes, útiles y pertinentes para demostrar la responsabilidad penal del acusado, vinculados a actos de corrupción; ello, no será suficiente para la celeridad del proceso, puesto que será aquí donde se notará desidia por parte de los jueces de juzgados de investigación preparatoria y de juzgamiento, debido a que no se esmerarán en fijar plazos cortos para las audiencias respectivas.

Seguro más de uno podrá discrepar lo expuesto líneas arriba, alegando que pese a la imprescriptibilidad de los delitos de corrupción en supuestos más graves del catálogo de tipos penales contra la administración pública, los plazos establecidos en las distintas etapas e instancias del proceso penal se cumplirían, puesto que el Código Procesal Penal de 2004, regula plazos para cada actuación procesal; al respecto corresponde refrescar la memoria, que en la praxis, tanto fiscales como jueces no cumplen con dichos plazos, por el contrario se resguardan en motivaciones y fundamentos aparentes, de que el caso concreto contendría cierta complejidad $\mathrm{y} / \mathrm{o}$ especial dificultad, 
cuando en realidad no cumplen con dichos estándares para ser calificados como tal, en conclusión los plazos previstos por la norma adjetiva no se cumplen; asimismo, se incrementaría el índice de juicios quebrados, puesto que la imprescriptibilidad originará parsimonia en jueces unipersonales y/o colegiados.

Por otro lado, es preciso señalar que, no solo la imprescriptibilidad de delitos de corrupción afectaría el derecho al plazo razonable, sino también al principio de proporcionalidad e igualdad. La persecución perpetua de los delitos de corrupción más graves, considerando que estos no son tan graves a comparación de otros delitos que protegen bienes jurídicos base, que dan génesis a otros bienes jurídicos, tales como el homicidio calificado, feminicidio, extorsión, secuestro, robo agravado u otros, sería claro ejemplo que se afectaría el derecho a la igualdad de otros tantos valores salvaguardados por el ordenamiento jurídico penal, en consecuencia tal medida recae en desproporcional, obligando que los delitos aludidos también sean declarados imprescriptibles, y ello no podría ser concebible por el derecho.

Antes de la reforma constitucional del artículo 41 de la Carta Fundamental, en similares líneas LOZA AVALOS aportaba, "No estamos aquí alegando que aquellos delitos graves o más graves que los de corrupción deban ser imprescriptibles, lo que estamos haciendo es advertir que su implementación constituirá una medida peligrosa que puede luego desencadenar igual exigencia frente a los otros delitos y extenderse peligrosamente" (Loza, 2017); pues tal vaticinio no duro mucho, ya que el pasado 24 de agosto de 2018 se publicó en el Diario Oficial El Peruano, la Ley $\mathrm{N}^{\circ} 30838$, incorporando el artículo 88-A del Código Penal, disponiendo que la mayoría de los delitos contra la libertad sexual, junto al proxenetismo, actos contra el pudor, trata de personas y esclavitud, no prescriben; por cierto estos delitos de lejos son mucho más graves que los delitos de corrupción, por ende merece reflexionar.

\section{CONCLUSIONES}

No hay duda, que la corrupción en Perú es un problema creciente, óbice para el desarrollo de la educación, salud, cultura y economía. La misma, se practica en todos los niveles o sectores del Estado, desde las pequeñas hasta las más grandes esferas de poder, ello trae consigo consecuencias nefastas, verbigracia: 1) Disuade que podamos contar con una economía sólida y desarrollada; 2) Progresiva ola de inseguridad ciudadana; 3) Lánguida ejecución de obras de primera necesidad como implementación y/o construcción de centros educativos y de salud; 4) Genera pobreza y desigualdad; y, 5) Etiqueta mala reputación al Perú como Estado a nivel internacional. En consecuencia, urge adoptar políticas de estado que desarraiguen la corrupción, con participación conjunta del Estado y la ciudadanía.

La imprescriptibilidad de la acción penal en delitos de corrupción, por más que solo opere en los supuestos más graves -conforme regula la ley de reforma del artículo 41 de la Constitución-, no es el instrumento adecuado para la lucha contra los delitos de corrupción, tampoco logrará combatir su impunidad, y ni siquiera tiene carácter disuasivo; puesto que, los agentes de los delitos de corrupción (funcionarios, servidores, y el particular) seguirán delinquiendo cada vez más ingeniosamente, conformando organizaciones criminales, para evitar ser comprendidos en investigaciones y sanciones penales. En consecuencia, la imprescriptibilidad de la acción penal en delitos de corrupción, es una medida innecesaria para combatir la corrupción, toda vez que es suficiente los plazos fijados por el Código Penal (duplicidad de la prescripción) y el Código Procesal Penal (suspensión de la prescripción cuando se formaliza investigación preparatoria) para investigar, juzgar y sancionar a los agentes vinculados con delitos de corrupción.

La imprescriptibilidad de delitos de corrupción 
vulnera el derecho fundamental al plazo razonable, debido a que se afectará el derecho de los justiciables a ser investigados y juzgados en un plazo prudente o sin dilaciones. Ningún ciudadano está libre de ser investigado por presuntos actos de corrupción, toda vez que, de alguna manera, en cualquier momento de su existencia podrá ocupar cargos de poder o prestar servicios al Estado, o en su defecto contratar con él, y a consecuencia de ello podrían ser falazmente denunciados por situaciones que obedezcan a persecuciones políticas, venganza o evasión de responsabilidades, y no por ello serían perpetuamente investigados $\mathrm{y} / \mathrm{o}$ procesados, denigrando la reputación de una persona en caso lo fuera inocente. Por tanto, lo correcto sería que las partes de una investigación y/o proceso penal tengan derecho a conocer en un tiempo razonable su situación jurídica, siendo los resultados: el archivo, sobreseimiento, acusación y sentencia absolutoria o condenatoria.

\section{PROPUESTAS Y/O RECOMENDACIONES}

A corto plazo, para la lucha contra la corrupción e impunidad de la misma, se prioricen antes que una pena privativa de libertad, los siguientes: 1) Se dicten contra el procesado y/o allegados a este, según correspondan, medidas cautelares de

\section{REFERENCIAS BIBLIOGRÁFICAS}

-Acuerdo Plenario No 01-2010/CJ-116, F.J. 9, 10 y 11. (s.f.). Corte Suprema de la Republica, VI Pleno Jurisdiccional de las Salas Penales Permanente y Transitorias. Asunto: Prescripción: Problemas Actuales.

-Acuerdo Plenario $\mathrm{N}^{\circ}$ 03-2012/CJ-116, F.J. 10 y 11. (s.f.). Corte Suprema de la Republica, I Pleno Jurisdiccional Extraordinario Penal. Asunto: Sobre la necesidad de revaluar la Suspensión de la Prescripción dispuetsa en el Art. 339.1 del Código Procesal Penal. carácter real, como el embargo, orden de inhibición, incautación y decomiso; y, 2) Se sancionen con muerte civil a quien se halle culpable por delitos de corrupción, previa evaluación de sus antecedentes y la condición de procesados o sancionados por delitos de corrupción.

A largo plazo, para combatir de raíz los actos de corrupción, se deben aplicar políticas de prevención a través de la educación, con participación obligatoria del Estado, instituciones educativas, entidades públicas o privadas, ONGs, familia y de más medios de control social formal e informal, quienes deberán tener la tarea principal de difundir y educar a estudiantes desde el nivel inicial hasta la superior, que los actos de corrupción son la peor actividad que el ser humano pueda practicar, puesto que no coadyuvan en el desarrollo del país, toda vez que mientras unos cuantos incrementan su patrimonio de forma indebida o ilegal, la mayoría de los peruanos resultan afectados, debido a que se les recorta el acceso a la educación, salud, economía y demás servicios de primera necesidad, los cuales no permiten que países en vías de desarrollo como el nuestro prosperen.

Huamanga, diciembre 2018.

-Acuerdo Plenario $N^{\circ}$ 09-2007/CJ-116, FJ. 06 y 10. (s.f.). Recuperado el 27 de octubre de 2018, de http://www.derecho.usmp.edu.pe/cedp/jurispru dencia/Acuerdo\%20Plenario\%20N9_2007.pdf

-Corte Interamericana de Derechos Huamanos, Caso Genie Lacayo vs. Nicaragua F.J. 77. (29 de enero de 1997). Recuperado el 12 de julio de 2018, de http://www.corteidh.or.cr/docs/casos/articulos/ seriec_30_esp.pdf 
- Corte Suprema de Justicia, Casación N ${ }^{\circ}$ 66-2010. (s.f.). Recuperado el 10 de agosto de 2018, de Casaciones y Acuerdos Plenarios, Ministerio de Justicia y Derechos Huamanos:

http://sistemas3.minjus.gob.pe/sites/default/files/ documentos/portada/CAS ACIONES-YACUERDOS-PLENARIOS.pdf

-Diario Oficial El Peruano. (20 de agosto de 2017). Recuperado el octubre de 14 de 2018, de http://www.leyes.congreso.gob.pe/Documentos/2 016 2021/ADLP/Normas_Legales/30650LEY.pdf

-El Comercio. (Abril de 22 de 2018).

Recuperado el 11 de octubre de 2018, de https://elcomercio.pe/politica/corrupcionprincipal-problema-peru-noticia-513999

-FIDH - La corrupción socava la democracia y el acceso a los derechos fundamentales. (Abril de 2018). Recuperado el 07 de Octubre de 2018, de https://www.fidh.org/IMG/pdf/luttecorruption712 web-1_final.pdf

https://quesignificado.com/imprescriptible/. (s.f.). Recuperado el 30 de agosto de 2018

- La imprescriptibilidad de los delitos de corrupción de funcionarios. ¿Medida necesaria para evitar la impunidad?, 2012. (s.f.).

-Legis.pe. (21 de agosto de 2017).

Recuperado el 29 de septiembre de 2018, de https://legis.pe/opiniones-ley-imprescriptibilidaddelitos-corrupcion/

-Loza Avalos, G. (2017).

Recuperado el 10 de agosto de 2018, de http://www.detrasdelacortina.com.pe/images/dow nload/ImprescriptibilidadDelitosCorrupcion.pdf

-Loza Avalos, G. (28 de junio de 2017).

Editores Perú. Recuperado el 10 de 16 de 2018, de https://pe.ijeditores.com/pop.php?option=articulo $\&$ Hash $=42$ e4eff66fb5cf080638878856e 5 b 962

-Melgarejo Barreto, P. (2011). Curso de Derecho Procesa Penal . Lima: Jurista Editores .
-Morante Guerrero, L. E. (septiembre de 2017). La imprescriptibilidad de la acción penal en caso de delito contra la administración publica o que afecte el patrimonio del Estado.

Actualidad Gubernamental, x-1.

-Muñoz Conde, F. (1999). Teoría General del Delito (Segunda Edición ed.). Santa Fe de Bogota, Colombia: Editorial Temis.

-Neyra Flores, J. A. (2010). Manual del Nuevo Proceso Penal \& de Litigación Oral. Lima: Idemsa.

-Pariona Arana, R. (2012). (Y. M. Vivanco, Ed.) Estudios críticos sobre los delitos de corrupción de funcionarios en Perú, 17-30.

-Pereira, C. R. (27 de octubre de 2016). El Comercio. Recuperado el 11 de septiembre de 2018, de El juicio sin final:

https:/elcomercio.pe/opinion/colaboradores/juici o-final-roberto-pereira-275035

-Pestana Uribe, E. (2009). La Configuración Constitucional de los Derechos No Enumerados en la Clausula Abierta del Sistema de Derechos y Libertades. Gaceta Juridica, Guia 3.

-Prado Saldarriaga, V. (1996). Todo Sobre el Código Penal (Vol. Tomo I). Lima, Perú: Editorial Idemsa.

-Proyecto de Ley, Reforma del Art. 41 de la Cosntitución Política del Estado. (21 de octubre de 2016). Lima, Perú.

-Tribunal Constitucional, STC Exp. N. ${ }^{\circ}$ 010-2002AI/TCF.J. 166. (s.f.).

Recuperado el 20 de agosto de 2018, de Caso Marcelino Tineo Silva y más de 5,000 ciudadanos: http:/www.tc.gob.pe/jurisprudencia/2003/000102002-AI.html 